\title{
Article \\ Factors Influencing Children's Behavioral Problems: Results from a Longitudinal Study of British Children from Birth to Seven Years
}

\author{
Helen Cheng ${ }^{1}$ and Adrian Furnham ${ }^{2, *}$ (D) \\ 1 Department of Psychology, University College London, London WC1E 6BT, UK; h.cheng@ucl.ac.uk \\ 2 BI: Norwegian Business School, Nydalsveien 37, 0484 Oslo, Norway \\ * Correspondence: adrian@adrianfurnham.com or a.furnham@ucl.ac.uk
}

Citation: Cheng, H.; Furnham, A.

Factors Influencing Children's

Behavioral Problems: Results from a Longitudinal Study of British Children from Birth to Seven Years. Psychiatry Int. 2021, 2, 224-232. https://doi.org/10.3390/ psychiatryint 2020017

Academic Editor: Ana Adan

Received: 7 April 2021

Accepted: 2 June 2021

Published: 7 June 2021

Publisher's Note: MDPI stays neutral with regard to jurisdictional claims in published maps and institutional affiliations.

Copyright: (c) 2021 by the authors. Licensee MDPI, Basel, Switzerland. This article is an open access article distributed under the terms and conditions of the Creative Commons Attribution (CC BY) license (https:/ / creativecommons.org/licenses/by/ $4.0 /)$.

\begin{abstract}
This study explored a longitudinal data set of over 10,663 children at age 7 years to examine various psychological and sociological factors that possibly influenced their behavioural problems. Data were collected when cohort members were born, then 9 months old, and later at later at ages 3 and 7 years. Structural equation modelling showed that the family income, maternal psychological distress, the parent-child relationship, and maternal personality traits all had direct significant effects on children's behavioural problems, accounting for 42 percent of the total variance. The strongest predictor was parent-child relationship, followed by maternal emotional stability (low neuroticism) and the family poverty indicator.
\end{abstract}

Keywords: children's behavioural problems; family income; maternal depression; parent-child relationship; maternal personality traits; cross-sectional and longitudinal

\section{Introduction}

This study set out to study psychosocial and socio-demographic correlates of children's behavioural problems at age of 7 years. It has two advantages over many previous studies related to this topic [1]. We explored a sample of over 10,000 children; and it was among the first study to examine maternal personality traits, parent-child interaction, financial conditions and maternal mental health in influencing behavioural problems in early childhood [2].

Many previous studies have concentrated on one particular set of variables that influence a child's adaptation without taking cognizance of a number of other salient demographic, psychological and sociological variables that are implicated in the process [3]. Using structural equation modelling (SEM), this study allows us to explore to what extent each of these psychological and socio-demographic factors relate to children's behavioural problems, and how these factors influence each other in the first seven years of a child's live.

Many disciplines are interested in how, when and which factors in a child's early life influence their subsequent socio-emotional development. Most of this work has concentrated more on the role of the mother rather than the father. There is much evidence showing that maternal personality and mental health such as maternal depression has a detrimental effect on children's development [4-9]. Children of depressed parents are found to be two to five times, or with higher rates, more likely to develop behaviour problems than children of parents without depression. Maternal depression increased risk of child injury and children's externalizing behaviours [10]). For example, Phelan and colleagues [10] found that 94 medically attended injuries were reported in the 1106 children $(8.5 \%)$. Maternal depressive symptoms significantly increased the risk of child injury; injury risk increased $4 \%$ for every 1-point increase in depressive symptoms. Further, maternal depression also plays a role on treatment outcome for children with externalizing 
behavioural problems, that improvements in maternal depression were associated with improvements in children's externalizing behaviour [11].

Other studies argue that there might be a mutual influence between maternal depressive symptoms and children's characteristics. Earlier, Hammen, Burge, and Stansbury [12] tested a model showing that although children's outcomes 6 months later were caused by maternal functioning (including depression symptoms, role adjustment, and observed positive interaction), characteristics of the child also contribute to maternal functioning in a cycle of negative mutual influence [12]. In this study we examine the effect of maternal psychological distress on children's behavioural problems over six years later at age 7 years.

There is evidence showing that the parent-child relationship is of paramount importance to any child's development [13-15]. In a relevant study, Pianta and Egeland [16] examined the relationships between stress experienced by 183 mothers and mother-child interaction at 2 points in time. They found that there was a relation between personal stress and a less cooperative, more insensitive, more intrusive parenting style for mothers of girls. The current study is able to examine parent-child relationship assessed at 3 years and their behavioural problems four years later.

Relatively few studies examined the association between parental personality traits and children's behavioural problems. Maternal personality has been found to be associated with parenting style [17]. In one study, Coplan, Reichel, \& Rowan [18] explored the associations between maternal personality, child temperament, and parenting. They found that for emotionally dysregulated children, the relations between mothers' personality and parenting were particularly strong; mothers' Agreeableness was negatively associated with coercive parenting, and mothers' Neuroticism was associated with overprotecting parenting. The current study was able to examine parental personality traits Extraversion and Emotional Stability/Neuroticism in relation to children's behavioural problems.

There is evidence of the link between family socio-economic conditions and children's adjustment and development [19-24] and between economic deprivation and maternal depression and child development $[25,26]$. This study was able to examine family income at nine months and children's behavioural problems seven years later.

This study explores to what extent a set of psychological and socio-demographic factors influence children's behavioural problems using path model. We developed five hypotheses were formulated. (H1) Family poverty indicator would be significantly associated with children's behavioural problems; (H2) Maternal depression would be significantly associated with children's behavioural problems; (H3) Parent-child relationship would be significantly associated with children's behavioural problems; (H4) Maternal personality traits extraversion and emotional stability would be significantly associated with children's behavioural problems; (H5) Family poverty (socio-economics), maternal depression, parentchild relationship, and maternal personality traits would be independently associated with the outcome variable.

\section{Materials and Methods}

\subsection{Sample}

The study was based on Millennium Cohort Study (MCS) [27]. The sample design allowed for disproportionate representation of families living in areas of child poverty, and non-response rates in each sweep have been slightly higher for families in ethnic or disadvantaged areas compared with families in advantaged areas in the UK [28]. We explored data from this sample when they were 9 months old (18,552 families took part in the survey), 3 years old (15,590 families took part in the survey) and 7 years old (13,857 families took part in the survey). The following analyses are based on 10,663 children and their mothers for whom we have complete data on variables examined. In comparison to the original sample, the analytic sample contains relatively more socially privileged and better educated mothers. 


\subsection{Measures}

1. Family income: A family income indicator was calculated adjusted for the number and ages of the people in the family home. Those whose income was $60 \%$ below the UK median were considered in poverty [29].

2. Maternal psychological distress: This was done when participants were 9 months old We used the 9-item Rutter Malaise Inventory [30] which measures depression, anxiety and psychosomatic illness [31]. Cronbach's alpha was 0.75 .

3. Parent-child relationship: This was assessed by the mothers report at age 3 years using the Pianta scale [32], which had 15 items High scores revealed a healthy parent-child relationship. The alpha was 0.77 .

4. Maternal personality: Extraversion and Neuroticism/Emotional Stability were assessed at age 7 years, from the International Personality Item Pool (IPIP) [33]. Extraversion had 7 items (alpha 0.71) and Neuroticism/Emotional Stability had 8 items (alpha 0.69).

5. Children's behavioural problems: Mothers filled out the Strength and Difficulties Questionnaire (SDQ) [34-36] (Alpha 0.73) It had 25 items, and five scales: hyperactivity, emotional symptoms, conduct problems, peer problems and pro-social behaviour. In this study the four behavioural problems subscales were used as the outcome measures. Cronbach's alpha for hyperactivity was 0.79; emotional symptoms.66: conduct problems 0.62: for peer problems 0.61 .

\subsection{Procedure}

The authors know and have explored this complex data set which is fully available once registration has been done. This was also approved by the departmental ethic committee CEHP/514/2017. As to be expected there was an attrition rate over time as well as missing data. This has been carefully studied considering what is known about systematic drop out over the three surveys and considered acceptable for further analysis.

\section{Results}

We set out to explore the data through two analyses: first a straightforward correlational analysis between all the variables followed by structural equation modelling. In the latter, we modelled select variables, based on both our hypotheses and the correlational results according to time: i.e., when the select variables were assessed.

\subsection{Correlational Analysis}

Table 1 shows the basic findings Children's behavioural problems measures were significantly and positively associated with family poverty indicator and maternal distress, and significantly and negatively associated with parent-child relationship, and maternal extraversion and emotional stability $(p<0.001)$. There were gender differences. Boys had higher scores on hyperactivity, conduct problems, and peer problems, whereas girls had higher scores on emotional symptoms. Girls also had higher scores than boys on parentchild relationship $(p<0.01$ to $p<0.001)$. Thus hypotheses (H1) to (H4) were supported. 
Table 1. Pearson product-moment correlations of SDQ and other variables in the study.

\begin{tabular}{|c|c|c|c|c|c|c|c|c|c|c|c|c|}
\hline & Variables & $\begin{array}{l}\text { Mean } \\
\text { (SD) }\end{array}$ & 1 & 2 & 3 & 4 & 5 & 6 & 7 & 8 & 9 & 10 \\
\hline 1. & Gender & $\begin{array}{c}0.49 \\
(0.50)\end{array}$ & & & & & & & & & & \\
\hline 2. & $\begin{array}{l}\text { SDQ total } \\
\text { difficulties } \alpha \\
=0.73 .\end{array}$ & $\begin{array}{c}6.98 \\
(5.21)\end{array}$ & $-0.12 * * *$ & & & & & & & & & \\
\hline 3. & $\begin{array}{c}\text { Hyperactivity } \\
\alpha=0.79 .\end{array}$ & $\begin{array}{c}3.20 \\
(2.47)\end{array}$ & $-0.18^{* * *}$ & $0.81^{* * *}$ & & & & & & & & \\
\hline 4 & $\begin{array}{l}\text { Emotional } \\
\text { symptoms } \alpha \\
\quad=0.62 .\end{array}$ & $\begin{array}{c}1.43 \\
(1.68)\end{array}$ & $0.03^{* *}$ & $0.67^{* * *}$ & $0.29^{* * *}$ & & & & & & & \\
\hline 5. & $\begin{array}{c}\text { Cond } \\
\text { problems } \alpha= \\
0.66 .\end{array}$ & $\begin{array}{c}1.28 \\
(1.46)\end{array}$ & $-0.10^{* * *}$ & $0.74^{* * *}$ & $0.54^{* * *}$ & $0.35^{* * *}$ & & & & & & \\
\hline 6. & $\begin{array}{c}\text { Peer } \\
\text { problems } \alpha= \\
0.61 .\end{array}$ & $\begin{array}{c}1.07 \\
(1.47)\end{array}$ & $-0.06^{* * *}$ & $0.67^{* * *}$ & $0.34 * * *$ & $0.41^{* * *}$ & $0.33^{* * *}$ & & & & & \\
\hline 7. & $\begin{array}{l}\text { Family } \\
\text { income } \\
\text { Maternal }\end{array}$ & $\begin{array}{c}0.23 \\
(0.42)\end{array}$ & 0.01 & $0.21 * * *$ & $0.16^{* * *}$ & $0.11^{* * *}$ & $0.19^{* * *}$ & $0.18^{* * *}$ & & & & \\
\hline 8. & $\begin{array}{c}\text { psychological } \\
\text { distress } \alpha= \\
0.75 .\end{array}$ & $\begin{array}{l}1.56 \\
(1.66)\end{array}$ & -0.01 & $0.24^{* * *}$ & $0.17^{* * *}$ & $0.19^{* * *}$ & $0.20^{* * *}$ & $0.16^{* * *}$ & $0.13^{* * *}$ & & & \\
\hline 9. & $\begin{array}{l}\text { Parent-child } \\
\text { relationship }\end{array}$ & $\begin{array}{l}64.81 \\
(6.67)\end{array}$ & $0.05^{* * *}$ & $-0.40^{* * *}$ & $-0.33^{* * *}$ & $-0.23^{* * *}$ & $-0.36^{* *}$ & $-0.24^{* * *}$ & $-0.13^{* * *}$ & $-0.26^{* * *}$ & & \\
\hline 10. & $\begin{array}{c}\text { Maternal } \\
\text { extraversion } \\
\alpha=0.71\end{array}$ & $\begin{array}{l}19.82 \\
(4.92)\end{array}$ & 0.02 & $-0.20^{* * *}$ & $-14^{* *}$ & $-0.18^{* * *}$ & $0.12^{* * *}$ & $-0.17^{* * *}$ & $-0.08^{* * *}$ & $-0.17^{* * *}$ & $0.16^{* * *}$ & \\
\hline 11. & $\begin{array}{c}\text { Maternal } \\
\text { emotional } \\
\text { stability } \alpha= \\
0.69 .\end{array}$ & $\begin{array}{l}23.85 \\
(4.83)\end{array}$ & -0.01 & $-0.34^{* * *}$ & $-0.25^{* * *}$ & $-0.28^{* * *}$ & $-0.28^{* *}$ & $0.20 * * *$ & $-0.06^{* * *}$ & $-0.36^{* * *}$ & $0.28^{* * *}$ & $0.30^{* * *}$ \\
\hline
\end{tabular}

Note: Higher score indicated being female, a higher on the family poverty indicator, maternal psychological distress, positive parent-child relationship, maternal extraversion and maternal emotional stability, and on children's behavioural problems. ${ }^{* *} p<0.01 ;{ }^{* * *} p<0.001$.

\subsection{Structural Equation Modelling}

Structural Equation Modelling (SEM) was used to explore this data [37]. Figure 1 shows the standardised path coefficients. The error variance for each observable and latent variables are included in the model.

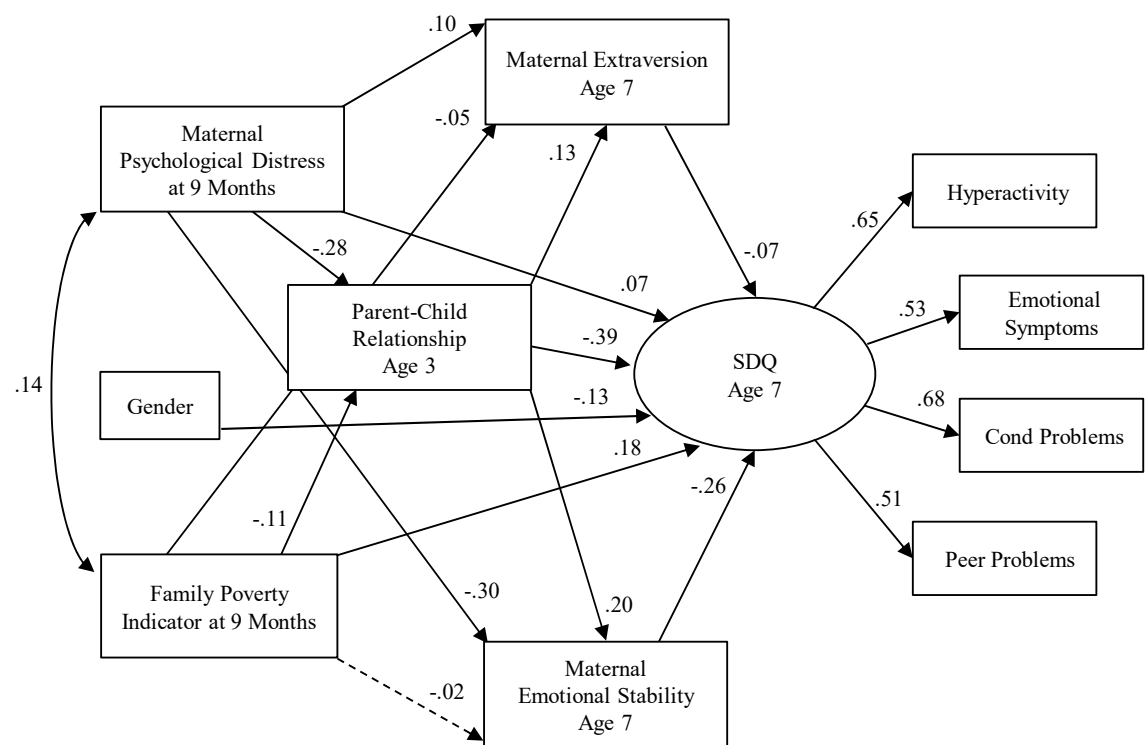

Chi-square $=563.4$

$d f=22$

CFI $=.968 ; \mathrm{TLI}=.930$

RMSEA $=.046$

Figure 1. Predicting children's behavioural problems path model. 


\subsection{Model Fit}

The $\chi^{2}$ statistic is overly sensitive when sample sizes are large, or the observed variables are non-normally distributed. The root mean square error of approximation (RMSEA) gives a measure of the discrepancy in fit per degrees of freedom $(<0.05$ indicates a good fit). The final index of choices are the Comparative Fit Index (CFI), and the Tucker Lewis Index (or Non-normed Fit Index) where values above 0.95 indicate a very good fit, and values $>0.90$ are interpreted as good [38].

Table 2 shows unstandardized estimate, standard error, and standardised estimate of each indicator of the latent variable and the predictors of the outcome variable for the complete SEM model. For the latent variable of children's behavioural problems, the loading ranged from 0.51 to 0.68 , indicating the coherence of the underling construct for the latent variable.

Table 2. Unstandardized estimate, standard error and standardised estimate of the latent and observable variables of SEM that predict children's behavioural problems.

\begin{tabular}{|c|c|c|c|}
\hline Variables & $\begin{array}{l}\text { Unstandardized } \\
\text { Estimate }\end{array}$ & Standard Error & $\begin{array}{l}\text { Standardised } \\
\text { Estimate }\end{array}$ \\
\hline \multicolumn{4}{|l|}{$\begin{array}{l}\text { Children's behavioural } \\
\text { problems (SDQ) }\end{array}$} \\
\hline Hyperactivity & 1.000 & & 0.646 \\
\hline $\begin{array}{l}\text { Emotional } \\
\text { symptoms }\end{array}$ & 0.569 & $0.016^{* * *}$ & 0.528 \\
\hline Cond problems & 0.637 & $0.004^{* * *}$ & 0.676 \\
\hline Peer problems & 0.483 & $0.014^{* * *}$ & 0.514 \\
\hline \multicolumn{4}{|l|}{$\begin{array}{l}\text { Predicting children's } \\
\text { behavioural problems }\end{array}$} \\
\hline Gender & -0.435 & $0.033^{* * *}$ & -0.135 \\
\hline $\begin{array}{l}\text { Family poverty } \\
\text { indicator }\end{array}$ & 0.645 & $0.036^{* * *}$ & 0.183 \\
\hline $\begin{array}{l}\text { Maternal } \\
\text { psychological distress }\end{array}$ & 0.065 & $0.010^{* * *}$ & 0.070 \\
\hline $\begin{array}{l}\text { Parent-child } \\
\text { relationship }\end{array}$ & -0.091 & $0.004^{* * *}$ & -0.386 \\
\hline $\begin{array}{l}\text { Maternal } \\
\text { extraversion }\end{array}$ & -0.029 & $0.004^{* * *}$ & -0.072 \\
\hline $\begin{array}{l}\text { Maternal emotional } \\
\text { stability }\end{array}$ & -0.094 & $0.003^{* * *}$ & -0.259 \\
\hline
\end{tabular}

The model showed a good fit. Chi-square was $563.4(d f=22, p<0.001)$, the CFI was 0.968 , the TLI was 0.930 , and the RMSEA was 0.046 . The model explains 42 per cent of the total variance of children's behavioural problems. Figure 1 shows that family poverty indicator, maternal depression, parent-child relationship, and maternal personality traits extraversion and emotional stability all had significant and direct effects on children's behavioural problems. Therefore (H5) was supported. The strongest predictor of children's behavioural problems was parent-child relationship, followed by maternal emotional stability and family poverty indicator. Gender was significantly associated with the outcome variable, boys had higher scores than girls on the latent behavioural problems variable.

Figure 1 indicates that family poverty was positively associate with maternal depression, and was a modest but significant negative predictor of parent-child relationship as well as maternal extroversion. Maternal depression was a significant negative predictor of parent-child relationship and maternal emotional stability, and a positive predictor of maternal extraversion. Parent-child relationship in turn, was a significant and positive predictor of both maternal personality traits.

As maternal depression and maternal emotional stability were considerably intercorrelated $(r=0.36, p<0.001)$ and were measuring similar psychological constructs, to 
ascertain the incremental effects of maternal personality traits on children's behavioural problems, the SEM was conducted again, removing the maternal traits variables from the equation.

The model also showed a good fit. Chi-square was 403.8 ( $d f=14, p<0.001)$, the CFI was 0.970 , the TLI was 0.923 , and the RMSEA was 0.049 . The model explains 34 per cent of the total variance of children's behavioural problems. This indicates that maternal personality traits emotional stability and extraversion had explained incrementally 8 per cent of variance of children's behavioural problems, after taking account other psychological and socio-demographic factors examined in the study. In this model, there was a slight increase of the path coefficients between parent-child relationship and the outcome variable (from 0.39 to 0.45 ), and between maternal depression and the outcome variable (from 0.07 to 0.15 ).

\section{Discussion}

The results of the current study show that all of the independent variables measured at different points in time, were significantly associated with children's behavioural problems. SEM results in Figure 1 show that family income, maternal distress and personality, parentchild relationship, all had significant and direct effects on children's behavioural problems.

In this sense we had a mixture of structural sociological variables and well as psychological variables in examining their effect on our outcome measure.

This study confirmed and extended the previous findings in the area. First, family economic deprivation was negatively associated with children's behavioural problems. Children who experienced family poverty at birth increased the risk of having behavioural problems at age 7 years. Family poverty was also significantly and positively associated with maternal depression, and significantly and negatively associated with parent-child relationship. Whilst this finding is well established the mechanism or process to explain it is not. Furthermore, the direction of causality may well be reciprocal in the sense that poverty causes increased distress which in turn effects many aspects of a persons' and families well being.

Second, maternal psychological distress had a modest but significant positive effect on children's behavioural problems six years later. Children whose mothers suffered psychological distress when they were 9 months old were more likely to have behavioural problems at age 7 years. Presumably this distress has an impact on the sensitivity and reliability of child care, which in turn, has an impact on the child's adaptation and socialization.

Maternal psychological distress also associated with maternal personality traits Extraversion and Emotional Stability. However, although personality was measured six years later than maternal psychological distress, as personality is relatively stable, it is possible maternal psychological distress is also affected by personality traits. Trait emotional stability is closely associated with distress and is stable over time [31] which explains the strongly significant relationships in Figure 1.

Maternal psychological distress is also a significant predictor of parent-child relationship. Mothers who experienced psychological distress are more likely to have negative parent-child relationship two years later, when their children were three years old. As psychological distress is relatively stable, it is possible that mothers who experienced psychological distress when their 9 month old children still had such psychological symptoms, and stressful parent-child relationship may worsen such condition. Indeed children of a distress and unstable mother no doubt experience many difficulties and deprivations that increase their behavioural problems.

Third, parent-child relationship was a significant and direct predictor of children's behavioural problems. Cohort members who had negative relationship with their mothers tended to have more behavioural problems four years later at age 7 years. Among all factors examined in the study, this factor was the strongest predictor of children's behavioural problems $(r=-0.40$ and path coefficient $=0.39)$, indicating the salient impotence of this factor. The extensive literature on attachment has described in detail how this process works [34]. 
Fourth, the present study shows that maternal personality traits Emotional Stability (i.e., low Neuroticism) and Extraversion explained incrementally 8 per cent variance of children's behavioural problems, taking account the effects of family poverty indicator, maternal psychological distress, parent-child relationship on the outcome variable. This has specific implications for the treatment on children's behavioural problems. Interventions and treatment on children's behavioural problems might have more effective if parental personality trait, such as Emotional Stability, is taken into account. Mothers who are emotionally unstable are more prone to anxiety, depression and psycho-somatic illness and need extra help and advice on their coping skills.

Although there is a considerable overlap between psychological distress and Emotional Stability ( $r=-0.36$ in the study), these two measures may have different components. For example, psychological distress is more related to psychiatric symptoms, whereas trait Emotional Stability is more related to negative affect. Without physical symptoms, maternal Emotional Stability in likely not to be acknowledged in the treatment of children's behavioural problems. Yet, the current study demonstrates that this factor explained the unique variance of children's behavioural problems.

One very important point needs to be made. This study is all about the maternal model of the family: notably the role of the mother. We did this because of the data available. We recognize that fathers increasingly play a fundamental and continuing role in the earlier and later development of the child, Hopefully these issues can be explored in later studies.

\section{Conclusions}

A number of factors are implicated in the development of behavioural problems in mid childhood. In this study we found further evidence of a pathway from maternal distress soon after birth ( 9 months), having a direct impact on the mother child relationship when the child is 3 years old, and which is a powerful predictor of childhood behavioural problems fours year later at age 7 years. Clearly, the sooner some sort of intervention in this causal sequence occurs the better it is for all concerned particularly the distress mother and the poorly adjusted child.

\section{Limitations}

Like all studies, this study had limitations. As with all research using cohort studies, the variables used in the study is constrained by the availability of the data. Another limitation is the attrition of respondents over time. Since sample attrition is greatest amongst individuals in more deprived circumstances, our results may thus be a conservative estimate of the long-term influence of social inequalities experienced during early childhood. Also all our data was based on mother-reports with concomitant problems of method invariance. Further, it would be desirable to have maternal personality measured earlier, at the birth of cohort members.

Author Contributions: H.C. and A.F. conceived the idea; H.C. conducted the analysis and drafted the paper; A.F. re-wrote the paper; A.F. and H.C. revised the paper. All authors have read and agreed to the published version of the manuscript.

Funding: This research received no external funding.

Institutional Review Board Statement: This study used data from an open access website.

Informed Consent Statement: Not applicable.

Data Availability Statement: This is an open access website (http:/ /ukdataservice.ac.uk; accessed on 1 June 2021).

Conflicts of Interest: The authors declare no conflict of interest. 


\section{References}

1. Escalante-Barrios, E.L.; Suarez-Enciso, S.M.; Raikes, H.; Davis, D.; Garcia, A.; Gonen, M.; Veziroglu-Celik, M.; Hazar, R.G. Childparent interactions in American and Turkish families: Examining measurement invariance analysis of child-parent relationship scale. PLoS ONE 2020, 15, e0230831. [CrossRef]

2. Pensiero, N.; Schoon, I. Social inequalities in educational attainment: The changing impact of parents' social class, social status, education, and family income, England 1986 and 2010. Longitud. Life Course Stud. 2019, 10, 87-108. [CrossRef]

3. Driscoll, K.; Pianta, R.C. Mothers' and fathers' perceptions of conflict and closeness in parent-child relationships during early childhood. J. Early Child. Infant Psychol. 2011, 7, 1-24.

4. Bornstein, M.H.; Hahn, C.; Haynes, O.M. Maternal Personality, Parenting Cognitions, and Parenting Practices. Dev. Psychol. 2011, 47, 658-675. [CrossRef] [PubMed]

5. Conroy, S.; Pariante, C.M.; Marks, M.N.; Davies, H.A.; Farrelly, S.; Schacht, R.; Moran, P. Maternal psychopathology and infant development at 18 months: The impact of maternal personality disorder and depression. J. Am. Acad. Child. Adolesc. Psychiatry 2012, 51, 51-61. [CrossRef] [PubMed]

6. Cummings, E.M.; Davies, P.T. Maternal depression and child development. J. Child Psychol. Psychiatry 1994, 35, 73-122. [CrossRef] [PubMed]

7. He, G.-H.; Liu, L.; Strodl, E.; Ruan, Z.-L.; Jiang, H.; Jing, J.; Jin, Y.; Chen, W.-Q. Parental Type D Personality and Children's Hyperactive Behaviors: The Mediating Role of Parent-Child Interactive Activities. Int. J. Environ. Res. Public Health 2019, 16, 1116. [CrossRef] [PubMed]

8. Nath, S.; Pearson, R.; Moran, P.; Pawlby, S.; Molyneaux, E.; Howard, L.M. Maternal personality traits, antenatal depressive symptoms and the postpartum mother-infant relationship: A prospective observational study. Soc. Psychiatry Psychiatr. Epidemiol. 2020, 55, 621-634. [CrossRef] [PubMed]

9. Rutter, M.; Quinton, D. Parental psychiatric disorder: Effects on children. Psychol. Med. 1984, 14, 853-880. [CrossRef]

10. Phelan, K.; Khoury, J.; Atherton, H.; Kahn, R.S. Maternal depression, child behavior, and injury. Inj. Prev. 2007, 13, 403-408. [CrossRef]

11. Van Loon, L.M.; Granic, I.; Engels, R.C. The role of maternal depression on treatment outcome for children with externalizing behavior problems. J. Psychopathol. Behav. Assess. 2011, 33, 178-186. [CrossRef] [PubMed]

12. Hammen, C.; Burge, D.; Stansbury, K. Relationship of mother and child variables to child outcomes in a high-risk sample: A causal modelling analysis. Dev. Psychol. 1990, 26, 24-30. [CrossRef]

13. Pianta, R.C. Adult-Child Relationship Processes and Early Schooling. Early Educ. Dev. 1997, 8, 11-26. [CrossRef]

14. Morris, A.; Criss, M.; Silk, J.; Houltberg, B. The impact of parenting on emotion regulation during childhood and adolescence. Child Dev. Perspect. 2017, 11, 233-238. [CrossRef]

15. Slagt, M.; Dubas, J.; Dekovic, M.; van Aken, M. Differences in sensitivity to parenting depending on child temperament: A meta-analysis. Psychol. Bull. 2016, 142, 1068-1110. [CrossRef]

16. Pianta, R.C.; Egeland, B. Life stress and parenting outcomes in a disadvantaged sample: Results of the mother-child interaction project. J. Clin. Child Psychol. 1990, 19, 329-336. [CrossRef]

17. Bahrami, B.; Dolatshahi, B.; Pourshahbaz, A.; Mohammadkhani, P. Comparison of Personality among Mothers with Different Parenting Styles. Iran. J. Psychiatry 2018, 13, 200-206.

18. Coplan, R.J.; Reichel, M.; Rowan, K. Exploring the associations between maternal personality, child temperament, and parenting: A focus on emotions. Pers. Individ. Differ. 2009, 46, 241-246. [CrossRef]

19. Gershoff, E.T.; Aber, J.L.; Raver, C.C.; Lennon, M.C. Income is not enough: Incorporating material hardship into models of income associations with parenting and child development. Child Dev. 2007, 78, 70-95. [CrossRef]

20. Hertzman, C.; Siddiqi, A.; Hertzman, E.; Irwin, L.G.; Vaghri, Z.; Houweling, T.A.J.; Marmot, M. Bucking the inequality gradient through early child development. Br. Med. J. 2010, 340, c468. [CrossRef]

21. Marmot, M. Fair Society Healthy Lives. The Marmot Review: Strategic Review of Health Inequalities in England Post 2010. 2010. Available online: http:/ / www.ucl.ac.uk/gheg/marmotreview /FairSocietyHealthyLives (accessed on 1 June 2021).

22. McLoyd, V.C. Socioeconomic disadvantage and child development. Am. Psychol. 1998, 53, 185-204. [CrossRef] [PubMed]

23. McLoyd, V.C.; Flanagan, C.A. Economic Stress: Effects on Family Life and Child Development; Jossey-Bass: San Francisco, CA, USA, 1990.

24. Taylor, B.; Dearing, E.; McCartney, K.A. Incomes and outcomes in early childhood. J. Hum. Resour. 2004, 39, 980-1007. [CrossRef]

25. Kiernan, K.E.; Huerta, M.C. Economic deprivation, maternal depression, parenting and children's cognitive and emotional development in early childhood. Br. J. Sociol. 2008, 59, 783-806. [CrossRef]

26. Petterson, S.M.; Albers, A.B. Effects of poverty and maternal depression on early child development. Child Dev. 2011, 72, 1794-1813. [CrossRef] [PubMed]

27. Dex, S.; Joshi, H. Children of the 21st Century: From Birth to Nine Months; Policy Press: Bristol, UK, 2005.

28. Ketende, S. Technical Report on Response; Centre for Longitudinal Studies, Institute of Education: London, UK, 2010.

29. Ketende, S.; Joshi, H. Income and poverty. In Millennium Cohort Study, Third Survey: A User's Guide to Initial Findings; Hansen, K., Joshi, H., Eds.; Centre for Longitudinal Studies, Institute of Education: London, UK, 2008.

30. Rutter, M.; Tizard, J.; Whitmore, K. Education, Health and Behaviour; Longmans: London, UK, 1970. 
31. Furnham, A.; Cheng, H. The stability and change of malaise scores over 27 years: Findings from a nationally representative sample. Pers. Individ. Differ. 2015, 79, 30-34. [CrossRef]

32. Pianta, R.C. Parent-Child Relationship Scale; University of Virginia: Richmond, VA, USA, 1992.

33. Goldberg, L.R. A broad-bandwidth, public domain, personality inventory measuring the lower level facets of several five-factor models. In Personality Psychology in Europe; Mervielde, I., Deary, I., De Fruyt, F., Ostendorf, F., Eds.; Tilburg University Press: Tilburg, The Netherlands, 1999; Volume 7, pp. 7-28.

34. Goodman, A.; Goodman, R. Strengths and Difficulties Questionnaire as Dimensional Measure of Child Mental Health. J. Am. Acad. Child Adolesc. Psychiatry 2009, 48, 400-403. [CrossRef]

35. Goodman, R. The strengths and difficulties questionnaire: A research note. J. Child Psychol. Psychiatry 1997, 38, 581-586. [CrossRef]

36. Goodman, R. Psychometric properties of the strengths and difficulties questionnaire (SDQ). J. Am. Acad. Child Adolesc. Psychiatry 2001, 40, 1337-1345. [CrossRef] [PubMed]

37. Arbuckle, J.L. Full information estimation in the presence of incomplete data. In Advanced Structural Equation Modelling; Marcoulides, G.A., Schumacker, R.E., Eds.; Lawrence Erlbaum Associates, Inc.: Mahwah, NJ, USA, 1996; pp. $243-277$.

38. Bentler, P.M. Comparative fit indexes in structural models. Psychol. Bull. 1990, 107, 238-246. [CrossRef] 